\title{
Psychiatric comorbidities, oral health, and comprehensive
}

\section{care}

\author{
Sonali Sarkar* \\ Department of Psychiatry, University of Texas Health Science Center, 7703 Floyd Curl Drive, San Antonio, Texas 78229, USA
}

\begin{abstract}
Patients' with psychiatric comorbidities (schizophrenia, affective disorder/depression, mental retardation etc.) often exhibit poor oral health and dental hygiene. Potential etiologic factors for poor oral health are psychiatric comorbidities, neurological disorders, medication side-effect (dryness of mouth, hyposalivation), binge eating/induction of vomiting in eating disorders, substance abuse (smoking nicotine/cannabis, drinking alcohol), nutritional deficiency, poor self-care and bad oral hygiene. The rising trend of poor oral health and dental complications (dental caries, infection, tooth decay, tooth loss) among psychiatric patients poses a significant public health problem. Mental and dental health practitioners often lack the time and effort to address this vital public health issue in their practice. This review article highlights the clinical association between psychiatric comorbidities and poor oral health that has important practice implications. Additionally, this article provides practice guidelines for comprehensive care among psychiatric patients with poor oral health.
\end{abstract}

\section{Introduction}

Patients' with psychiatric comorbidities (schizophrenia, affective disorder/depression, mental retardation etc.) often exhibit poor oral health and dental hygiene [1]. This could be due to lifestyle factors and poor self-care. Oral health needs of patients' with psychiatric comorbidities are complex and need to be addressed by both mental and dental health practitioners. Public health problem of poor oral health is often overlooked and underreported in this underrepresented population of patients with psychiatric comorbidities.

Review of literature indicates dental health practitioners' not only lack adequate skills or awareness for treating special needs population but also exhibit communication barriers, attitude and avoidant behaviors for dealing with difficult to treat mentally disabled psychiatric patients [2]. Conversely, mental health practitioners report barriers (time constraints, lack of skills or training) and fail to address oral health and dental hygiene among patients with psychiatric comorbidities [3]. Both mental and dental health practitioners might benefit from tailored intervention coupled with awareness and skills training to treat dental health problems among patients with psychiatric comorbidities [1,3]. There also exists a research gap as there are limited number of studies examining the association between psychiatric comorbidities and oral health. Majority of the studies are observational vs. interventional and are limited by small sample size [4,5]. Prior research studies conducted in this field not only have limitations in adequate control of confounding variables but also lack standardized research tools to assess the efficacy of conducting oral health intervention among patients' with psychiatric comorbidities [4,5]. Thus evidence based dentistry is lacking in this population. This review article highlights the clinical association between psychiatric comorbidities and poor oral health that has important practice implications. Additionally, this article provides practice guidelines for comprehensive care among psychiatric patients with poor oral health.

\section{Methods}

A search for online databases: MED-LINE, Pubmed, PsychLit, Googlescholar was performed. Only articles published in English language globally between the time interval 2000-2016 were considered for inclusion. Both adults (males \& females) and youths (child and adolescents) were included. The search terms used were "psychiatry", "comorbidities", "schizophrenia", "depression”, "eating disorder", "substance abuse", "addiction", "smoking", "nicotine", "alcohol", "cannabis", "intellectual disability", "oral health", "dental hygiene", "dental caries" "tooth decay", "dental health", "etiology", "pathophysiology", "clinical”, "dentistry", "practice”, "implications", and "comprehensive care". These search terms were used in combination with each other using the conjunctions "AND" and "OR". The initial review yielded 884 articles. The articles were reviewed one by one. The reference section of the articles considered for the initial review yielded a few articles that were included in subsequent review. Finally, only 66 recent articles that were relevant to the topic were included for the final review.

\section{Results}

\section{Epidemiology}

The prevalence of poor oral health and dental hygiene (61\%) among patients with psychiatric comorbidities is higher than the general population [6,7]. Patients' with mental disability are 2.5 times

Correspondence to: Sonali Sarkar, Department of Psychiatry, University of Texas Health Science Center, 7703 Floyd Curl Drive, San Antonio, TX 78229. USA; Tel (210) 567-2400; Fax (210) 667-9800; E-mail: sonalisarkar@yahoo.com

Key words: psychiatry, comorbidities, oral health, dental hygiene, comprehensive care

Received: December 19, 2016; Accepted: February 10, 2017; Published: February 13, 2017 
more likely than the general population to experience tooth decay [8]. Patients' with psychiatric illness have 3.4 times the odds of teeth loss than the general community [9]. Factors contributing to the increased prevalence of poor oral health among mentally ill could be avoidance behavior to seek dental care due to the fear of pain or dental phobia which could also be exacerbated by the cost of dental care. The prevalence of dental phobia is reported to be $24.3 \%$ which may prevent dental visit [10]. Fear of dental treatment and procedures is associated with female gender, often rated severe than any other fear and is strongly associated with intrusive re-experiencing (49.4\%) [10]

Poor oral health is observed not only among adults with psychiatric comorbidities but also in children and adolescents'. Prevalence of dental caries among children with mental disabilities is reported to be approximately 50-60\% [5]. Dental health services are often underutilized by patients' with psychiatric comorbidities (schizophrenia and affective disorders, mental retardation) and therefore, represents an unmet need [11]

\section{Etiology}

\section{Psychiatric comorbidities}

\section{Schizophrenia}

Patients with psychiatric comorbidities like schizophrenia have poor oral health and exhibit tooth decay, missing teeth, dental caries, and consequent dental filling [12]. Poor oral health with dental caries and missing teeth is observed not only among outpatient schizophrenic patients but also in chronically hospitalized psychiatric inpatients with schizophrenia and difficult to treat psychiatric comorbidities [13]. Patients with schizophrenia have halitosis (bad breath) which is an indicator of poor oral health and dental hygiene [14]. Poor oral health (dental caries, decay and tooth loss) is not only associated with categories and types of psychiatric diagnosis but also with the number of psychotropic medications [15]. Increasing age, treatment anxiety, neglect of tooth-brushing and chronic ward inpatients are significant predictors of poor oral health reported in patients with psychiatric comorbidities [16].

\section{Affective disorders}

Affective disorder specifically symptoms of depression along with anxiety are associated with poor oral health including low toothbrush frequency [17]. During depression (Major Depressive Disorder or Bipolar depression), many patients exhibit fatigue, lack of interest or motivation for self-care and a decline in the level of oral hygiene which increases the prevalence of dental caries and periodontal disease [18]. Factors that influence oral health include type, severity and stage of psychiatric comorbidity, mood, motivation, self-esteem, socio-economic status, self-care, lifestyle, habit (smoking, drinking), attitude, knowledge and self-perception of the health problem [19, 20]. Additionally, severely depressed patients have priorities other than their oral health, may lack facilities or privacy for oral hygiene owing to poor housing or homelessness. These factors indicate that there exists an association between mental health and oral health [19].

\section{Eating disorders}

Patients' with psychopathological conditions like eating disorders (Anorexia nervosa and Bulimia nervosa) have poor oral health and dental complications [21]. The dental implications of eating disorder include dental enamel erosion (due to pica, vomiting and toothwear), teeth decalcification from gastric acid exposure due to vomiting induction (perimylolysis), enlargement of salivary glands (parotids), hyposalivation, dryness of mouth, dental caries (due to consumption of high-carbohydrate foods and intake of sugary and carbonated beverages) [22-24]. Oral manifestations of eating disorders are caused by numerous factors including nutritional deficiencies, metabolic derangements, nutritional habits (binge eating and induction of vomiting in Bulimia patients), and poor dental hygiene [25].

\section{Mental retardation}

Patients with mental retardation and intellectual disabilities including children with autism, Down's syndrome, learning disabilities are more likely to have dental caries, periodontal disease and poor oral health [26-28]. Older adults with lower cognitive function as noted by lower scores on Mini Mental Status Exam (MMSE=0-23) have a higher risk of dental (coronal and root) caries [29]. Additionally, older adults with lower cognitive function (MMSE=0-23) demonstrate four times higher risk of not utilizing regular dental care services [29]. Patients with intellectual disabilities and mental retardation lack cognitive skills and physical coordination to perform complex tasks like daily tooth brushing and flossing [30]. Thus, poor oral health is noted among mentally retarded and intellectually disabled individuals.

\section{Neurological disorders}

Patients' with neurological disorders especially Parkinson's disease (PD) have more dental caries and fewer remaining teeth [31]. Postural instability and bradykinesia may prevent dental visits in this patient population thereby predisposing them to poor oral health and dental complications [31]. Patients with dementia and Alzheimer's disease also exhibit poor oral health and need comprehensive dental care [32]. Cognitive dysfunction (learning and memory problems) along with functional and behavioral changes interferes with patients' ability to perform oral hygiene techniques ultimately increasing the prevalence of dental disease in older patients with Alzheimer's disease [33]. Therefore, poor oral health is observed in patients with neurological disorders.

\section{Medication side-effect}

Psychotropic medications (antidepressant and antipsychotics) block the cholinergic receptors, cause reduced salivary flow and produce dryness of mouth (xerostomia). Dryness of mouth is associated with decreased salivary flow rate and enzymatic action causing bacterial overgrowth and yeast (candida) infections [13, 18, 34]. Hyposalivation and dryness of mouth is also associated with increased incidence of infections, fissuring of corners of mouth, cracking of lips, and difficulty chewing, speaking and swallowing $[35,36]$. Dryness of mouth decreases the overall quality of life, increases plaque and calculus formation and therefore leads to a higher incidence of dental caries, gingivitis and periodontitis $[13,18,37]$.

\section{Addiction and substance abuse}

Addiction and substance abuse (nicotine, alcohol, illegal drugs) is associated with poor oral health, bad dental hygiene and complications [38-41]. Smoking and chewing nicotine products leads to tar deposition and teeth coloration, an increased incidence of dental erosion, mucosal burns, keratotic patches, cervical abrasion and gingival necrosis [42]. Among alcohol dependent individuals poor oral health and decreased saliva secretion increases the risk of dental caries, burning mouth syndrome, halitosis, and oral infections (gingivitis, stomatitis, glossitis, angular cheilitis, leukoplakia of the tongue) [43]. Alcohol and drug abusers combined have a significantly higher risk of having tooth decay compared to alcohol abusers alone [44]. 


\section{Nutritional deficiency}

Poor oral health in patients with psychiatric comorbidities often leads to functional difficulties (tooth pain, tooth loss) and makes it difficult for them to eat nutritional food [45]. Nutritional deficiency associated with low fruits and vegetable intake in older adults with low socio-economic status is associated with loss of teeth (edentulousness) [46].

\section{Self-care and oral hygiene}

Oral care is important in the prevention of dental infections and complications [47]. Lack of daily self-care, regular tooth- brushing, oral hygiene maintenance is associated with oral infections, dental caries and tooth loss among patients with psychiatric comorbidities.

\section{Discussion}

Prior studies have addressed dental practice guidelines in patients with psychiatric comorbidities [33, 48-53]. These include

\section{Comprehensive care}

1. Psychiatrists and mental health practitioners should take the time and effort to elicit a dental history, conduct an oral exam along with performing general physical examination.

2. Psychiatrists and mental health practitioners should address psychotropic medication side-effects like dryness of mouth (xerostomia) and prescribe salivary substitutes and stimulants.

3. Psychiatrists should perform a comprehensive dental evaluation and ask for a dental consultation and follow up as necessary.

4. Psychiatrists and mental health practitioners should educate their patients about maintaining good dental hygiene, daily flossing, advocate usage of anti-caries agent (fluoridated toothpaste) and Chlorhexidine mouth rinses.

5. Training of dental health practitioners, inclusion of special care dentistry in dental school curriculum for early identification of oral cues of eating disorders, substance abuse and provision of comprehensive dental care should be advocated for difficult to treat patients with psychiatric comorbidities.

6. Dental health practitioners should consult with psychiatrists about patient's current medication regimen, degree of compliance with pharmacotherapy, current mental status and psychological profile.

7. Dental health practitioners should consider and provide adequate sedation, analgesia, mouth-guards, restraints and standby personnel while conducting dental exam and procedures on violent, unpredictable, difficult to treat patients with psychiatric comorbidities.

8. Both mental and dental health practitioners should discuss the adverse effects from dental procedures, dental pain analgesic and psychotropic medication prescription, dose management, potential drug interactions, and adverse effect.

9. Both mental and dental health practitioners should avoid or use reduced dosages of sedative and hypnotic agents and narcotic analgesics in their practice.

10. Both mental and dental health practitioners should undertake preventive education program including oral hygiene instruction, frequent recall appointments, advocate regular brushing of teeth with fluoridated toothpaste and promote dietary counseling.
11. Oral health promotion program for people with psychiatric disabilities should include a combination of mechanical toothbrush, dental instructions and reminders.

\section{Public health significance}

Poor oral health poses a significant public health problem in patients with psychiatric comorbidities [54,55]. There is a greater need for addressing oral health issues and comprehensive care among patients with psychiatric comorbidities which is an understudied population. Future public health research should focus on oral health promotion in patients' with psychiatric comorbidities.

\section{Conflict of interest}

The author reports no conflict of interest.

\section{Acknowledgement}

None.

\section{References}

1. Kadia S, Bawa R, Shah H, Narang P, Lippmann S (2014) Poor oral hygiene in the mentally ill: Be aware of the problem, and intervene. Curr Psychiatr 3: 47.

2. Cumella S, Ransford N, Lyons J, Burnham H (2000) Needs for oral care among people with intellectual disability not in contact with community dental services. $J$ Intellect Disabil Res 44: 45-52. [Crossref]

3. Baker R, Camosso-Stefinovic J, Gillies C, Shaw EJ, Cheater F, et al. (2015) Tailored interventions to address determinants of practice. Cochrane Database Syst Rev 4. [Crossref]

4. O'Keefe E (2010) Oral health of patients with intellectual disabilities. Evid Based Dent 11: 81. [Crossref]

5. Anders PL, Davis EL (2010) Oral health of patients with intellectual disabilities: a systematic review. Spec Care Dentist 30: 110-117. [Crossref]

6. Lewis D (2012) Summary of: prevalence of oral diseases and oral-health-related quality of life in people with severe mental illness undertaking community-based psychiatric care. Br Dent J 213: 462-3. [Crossref]

7. Matevosyan NR (2010) Oral health of adults with serious mental illnesses: a review. Community Ment Health J 46: 553-562. [Crossref]

8. Petrovic BB, Peric TO, Markovic DL, Bajkin BB, Petrovic D, et al. (2016) Unmet oral health needs among persons with intellectual disability. Res Dev Disabil 59: 370-377. [Crossref]

9. Kisely S, Quek LH, Pais J, Lalloo R, Johnson NW, et al. (2011) Advanced dental disease in people with severe mental illness: systematic review and meta-analysis. $\mathrm{Br} J$ Psychiatr 199: 187-93. [Crossref]

10. Oosterink FM, de Jongh A, Hoogstraten J (2009) Prevalence of dental fear and phobia relative to other fear and phobia subtypes. Eur J Oral Sci 117: 135-143. [Crossref]

11. Dickerson FB, McNary SW, Brown CH, Kreyenbuhl J, Goldberg RW, et al. (2003) Somatic healthcare utilization among adults with serious mental illness who are receiving community psychiatric services. Med Care 41: 560-70. [Crossref]

12. Arnaiz A, Zumárraga M, Díez-Altuna I, Uriarte JJ, Moro J, et al. (2011) Oral health and the symptoms of schizophrenia. Psychiatry Res 188: 24-28. [Crossref]

13. Ramon T, Grinshpoon A, Zusman SP, Weizman A (2003) Oral health and treatment needs of institutionalized chronic psychiatric patients in Israel. Eur Psychiatry 18: 101105. [Crossref]

14. Diz Dios P, Limeres Posse J, Tomás Carmona I (2000) Schizophrenia and halitosis. Oral Surg Oral Med Oral Pathol Oral Radiol Endod 89: 661. [Crossref]

15. Persson K, Axtelius B, Söderfeldt B, Ostman M (2009) Monitoring oral health and dental attendance in an outpatient psychiatric population. $J$ Psychiatr Ment Health Nurs 16: 263-271. [Crossref]

16. Teng PR, Su JM, Chang WH, Lai TJ (2011) Oral health of psychiatric inpatients: a survey of central Taiwan hospitals. Gen Hosp Psychiatry 33: 253-259. [Crossref]

17. Anttila S, Knuuttila M, Ylöstalo P, Joukamaa M (2006) Symptoms of depression and anxiety in relation to dental health behavior and self-perceived dental treatment 
need. Eur J Oral Sci 114: 109-114. [Crossref]

18. Sjögren R, Nordström G (2000) Oral health status of psychiatric patients. J Clin Nurs 9: 632-638. [Crossref]

19. Kisely S (2016) No Mental Health without Oral Health. Can J Psychiatry 61: 277-282. [Crossref]

20. DeHert M, Correll CU, Bobes J, Cetkovich-Bakmas M, Cohen D, et al. (2011) Physical illness in patients with severe mental disorders. I. Prevalence, impact of medications and disparities in health care. World Psychiatry 10: 52-77. [Crossref]

21. Frydrych AM, Davies GR, McDermott BM (2005) Eating disorders and oral health: a review of the literature. Aust Dent J 50: 6-15. [Crossref]

22. Ashcroft A, Milosevic A (2007) The eating disorders: 1. Current scientific understanding and dental implications. Dent Update 34: 544-546, 549-50, 553-4. [Crossref]

23. Aranha AC, Eduardo Cde P, Cordás TA (2008) Eating disorders. Part I: Psychiatric diagnosis and dental implications. J Contemp Dent Pract 9: 73-81. [Crossref]

24. Little JW (2002) Eating disorders: dental implications. Oral Surg Oral Med Oral Pathol Oral Radiol Endod 93: 138-143. [Crossref]

25. Lo Russo L, Campisi G, Di Fede O, Di Liberto C, Panzarella V, et al. (2008) Oral manifestations of eating disorders: a critical review. Oral Dis 14: 479-484. [Crossref]

26. Horwitz SM, Kerker BD, Owens PL, Zigler E (2000) Dental health among individuals with mental retardation. The health status and needs of individuals with mental retardation: Department of Epidemiology and Public Health, Yale University School of Medicine.119-28.

27. Traci MA, Seekins T, Szalda-Petree A, Ravesloot C (2002) Assessing secondary conditions among adults with developmental disabilities: a preliminary study. Ment Retard 40: 119-31. [Crossref]

28. U.S. Department of Health and Human Services (2000) Oral health in America: a report of the Surgeon General. Rockville, MD: U.S. Department of Health and Human Services, National Institute of Dental and Craniofacial Research, National Institutes of Health.

29. Avlund K, Holm-Pedersen P, Morse DE, Viitanen M, Winblad B (2004) Tooth loss and caries prevalence in very old Swedish people: the relationship to cognitive function and functional ability. Gerodontology 21: 17-26. [Crossref]

30. Owens PL, Kerker BD, Zigler E, Horwitz SM (2006) Vision and oral health needs of individuals with intellectual disability. Ment Retard Dev Disabil Res Rev 12: 28-40. [Crossref]

31. Hanaoka A, Kashihara K (2009) Increased frequencies of caries, periodontal disease and tooth loss in patients with Parkinson's disease. J Clin Neurosci 16: 1279-1282. [Crossref]

32. Ghezzi EM, Ship JA (2000) Dementia and oral health. Oral Surg Oral Med Oral Pathol Oral Radiol Endod 89: 2-5. [Crossref]

33. Friedlander AH, Norman DC, Mahler ME, Norman KM, Yagiela JA (2006) Alzheimer's disease: psychopathology, medical management and dental implications. $J$ Am Dent Assoc 137: 1240-51. [Crossref]

34. Shimizu C, Kuriyama T, Williams DW, Karasawa T, Inoue K, et al. (2008) Association of oral yeast carriage with specific host factors and altered mouth sensation. Oral Surg Oral Med Oral Pathol Oral Radiol Endod 105: 445-451. [Crossref]

35. Villa A, Abati S (2011) Risk factors and symptoms associated with xerostomia: a crosssectional study. Aust Dent J 56: 290-295. [Crossref]
36. Hopcraft MS, Tan C (2010) Xerostomia: an update for clinicians. Aust Dent J 55: 238244. [Crossref]

37. Thomson WM, Lawrence HP, Broadbent JM, Poulton R (2006) The impact of xerostomia on oral-health-related quality of life among younger adults. Health Qual Life Outcomes 4: 86. [Crossref]

38. Madinier I, Harrosch J, Dugourd M, Giraud-Morin C, Fosse T (2003) [The buccaldental health of drug addicts treated in the University hospital centre in Nice]. Presse Med 32: 919-923. [Crossref]

39. Laslett AM, Dietze P, Dwyer R (2008) The oral health of street-recruited injecting drug users: prevalence and correlates of problems. Addiction 103: 1821-1825. [Crossref]

40. Allam E, Zhang W, Zheng C, Gregory RL, Windsor LJ (2011) Smoking and oral health. Cigarette Smoke Toxicity: Linking Individual Chemicals to Human Diseases 257-80.

41. Petti S, Scully C, Wilson M (2009) Alcohol and oral health. Food constituents and oral health: current status and future prospects. 50-80

42. Mirbod SM, Ahing SI (2000) Tobacco-associated lesions of the oral cavity: Part I. Nonmalignant lesions. J Canad Dent Assoc 66(5): 252-6.

43. Pavicin IS, Karlovic D, Buljan D (2010) Alcoholism and Oral Health. Alcoholism: $J$ Alcohol Rel Addic 46(2).

44. Dasanayake AP, Warnakulasuriya S, Harris CK, Cooper DJ, Peters TJ, et al. (2010) Tooth decay in alcohol abusers compared to alcohol and drug abusers. Int J Dent 2010: 786503. [Crossref]

45. Kilbourne AM, Horvitz-Lennon M, Post EP, McCarthy JF, Cruz M, et al. (2007) Oral health in Veterans Affairs patients diagnosed with serious mental illness. $J$ Public Health Dent 67: 42-48. [Crossref]

46. Tsakos G, Herrick K, Sheiham A, Watt RG (2010) Edentulism and fruit and vegetable intake in low-income adults. J Dent Res 89: 462-467. [Crossref]

47. Xavier G (2000) The importance of mouth care in preventing infection. Nurs Stand 14: 47-51. [Crossref]

48. Clark DB (2003) Dental care for the patient with bipolar disorder. J Can Dent Assoc 69: 20-24. [Crossref]

49. Almomani F, Brown C, Williams KB (2006) The effect of an oral health promotion program for people with psychiatric disabilities. Psychiatr Rehabil J 29: 274-281. [Crossref]

50. Aranha AC, Eduardo Cde P, Cordás TA (2008) Eating disorders part II: clinical strategies for dental treatment. J Contemp Dent Pract 9: 89-96. [Crossref]

51. DeBate RD, Tedesco LA, Kerschbaum WE (2005) Knowledge of oral and physical manifestations of anorexia and bulimia nervosa among dentists and dental hygienists. $J$ Dent Edu 69(3): 346-54. [Crossref]

52. Coleman P (2002) Improving oral health care for the frail elderly: a review of widespread problems and best practices. Geriatr Nurs 23: 189-199. [Crossref]

53. Darby ML, Walsh M (2014) Dental hygiene: theory and practice. Elsevier Health Sciences.

54. McCreadie RG, Stevens H, Henderson J, Hall D, McCaul R, et al. (2004) The denta health of people with schizophrenia. Acta Psychiatr Scand 110: 306-10. [Crossref]

55. Kenkre AM, Spadigam AE (2000) Oral health and treatment needs in institutionalized psychiatric patients in India. Indian J Dent Res 11: 5-11. [Crossref]

Copyright: (C2017 Sarkar S. This is an open-access article distributed under the terms of the Creative Commons Attribution License, which permits unrestricted use, distribution, and reproduction in any medium, provided the original author and source are credited. 